\title{
Optimal Fiscal Policy with Consumption Taxation*
}

\author{
Giorgio Motta $^{\dagger} \quad$ Raffaele Rossi ${ }^{\ddagger}$
}

April 2018

JEL classification: E62, H21.

Keywords: fiscal policy, consumption taxation, endogenous government spending.

${ }^{*}$ We are grateful to the Editor (Kenneth D. West) and three anonymous referees as well as to Emanuele Bracco, Stefano Gnocchi, Sarolta Laczò, Dmitry Matveev, Monika Mertz, Maurizio Zanardi, Michela Cella, Andrea Colciago, Davide Debortoli and Nick Snowden, and to the seminar participants at the Bank of England, Bank of Holland, University of Milano-Bicocca, University of Durham, University of Vienna, University of Liverpool, University of Lancaster, University of Glasgow, the 2013 CEF conference in Vancouver, the 2014 T2M conference in Lausanne, the 2014 EEA meeting in Toulouse, the 2015 RES conference in Manchester, the 2017 RES conference in Bristol and the 2017 ICMAIF conference in Crete.

${ }^{\dagger}$ Department of Economics, Lancaster University Management School, LA1 4XY, Lancaster, United Kingdom. Email: g.motta@lancaster.ac.uk.

${ }_{\ddagger}^{\ddagger}$ Department of Economics, University of Manchester, M13 9PL, Manchester, United Kingdom. Email: raffaele.rossi@manchester.ac.uk. 


\begin{abstract}
We characterise optimal fiscal policies in a General Equilibrium model with monopolistic competition and endogenous public spending. The government can tax consumption, as alternative to labour income taxes. Consumption taxation acts as indirect taxation of profits (intratemporal gains of taxing consumption) and enables the policymaker to manage the burden of public debt more efficiently (intertemporal gains of taxing consumption). We show analytically that these two gains imply that the optimal share of government spending is higher under consumption taxation than with labour income taxation. Then, we quantify numerically each of these gains by calibrating the model on the US economy.
\end{abstract}




\section{Introduction}

In the past five decades most OECD countries have shifted their tax burden from income to consumption, mainly in the form of Value Added Tax. ${ }^{1}$ Since 1965, in these countries the share of consumption taxes as a percentage of GDP has more than doubled, from 3.2 percent to 6.9 percent in 2013. At the moment they raise more than 20 percent of total tax revenues on average, compared with 11.9 percent in 1965, (see OECD, 2014). For this reason, understanding the effects and relative merits of consumption taxation is crucial for the setting of economic policy and its role in pursuing fiscal stability, efficiency and welfare.

Along this line, this paper analyses both analytically and numerically the efficiency gains from taxing consumption by studying optimal fiscal policies in the vein of Ramsey (1927) (see also Lucas \& Stokey, 1983) in a tractable and deterministic Dynamic General Equilibrium model that abstracts from capital accumulation, where firms have monopolistic power, public spending directly increases households' utility and the government balances its budget by levying distortionary linear labour income and consumption taxes (but no lump-sum taxes) and by issuing risk-less bonds. Compared to a scenario where only labour income taxes are available, we identify and quantify two distinct benefits of taxing consumption and we map how these two benefits translates on the optimal provision of public spending and on households' welfare.

The first benefit is that consumption taxation serves as indirect taxation of inefficient profits, that otherwise would go untaxed under labour income taxation. We call this the intratemporal gains of taxing consumption. These intratemporal gains reduce the allocative inefficiency of monopolistic competition and disappear under perfect competition. The second benefit consists in consumption taxes acting as indirect taxation of the economy's initial level of the wealth, which is inelastically supplied and therefore can be taxed without distorting the economy. Given that wealth is entirely held under the form of government bonds, this one-time consumption tax in the initial period reduces debt and its burden in the longrun and in turn, compared with labour income taxation, also reduces the time inconsistency problem featured in Ramsey policy-making. We call this the intertemporal gains of taxing 
consumption. These intertemporal gains grow with the initial level of wealth (debt) and vanish when the initial level of wealth (debt) is zero. We prove analytically that due to these two efficiency gains, the optimal share of government spending is higher under consumption taxes than under labour income taxes. Finally, in a numerical exercise aimed to replicate some salient features of the US economy, we find that both the intratemporal and the intertemporal gains from taxing consumption are quantitatively important for the households' welfare. These gains hold under some important extensions of the baseline model, such as non-separability between leisure and consumption and complementarity-substitutability between private and public spending.

This paper links to the existing literature in two important ways. First, it contributes to the public finance literature that studies the welfare gains of taxing consumption, see Auerbach et al. (1983), Jones et al. (1993), Altig et al. (2001) and Trabandt \& Uhlig (2011) amongst others. On this, our closest contribution can be found in Coleman (2000), who finds, in a deterministic model with capital accumulation and perfect competition, that replacing income taxes with consumption taxes would lead to large welfare gains in the United States. Correia (2010) extends this result to a heterogeneous-agents framework. Two recent contributions highlight the role of consumption taxation as a tool to relax a constraint of the monetary authority on the nominal interest rate, either as a result of the zero lower bound (Correia et al. , 2013) or in a monetary union (Farhi et al. , 2014). However none of these contributions highlights and quantifies the interactions of consumption taxation with the market structure of the economy, public debt and government spending.

Second, we contribute to the literature, pioneered by Samuelson (1954), on the optimal provision of public goods. On this theme, Adam (2011) analyses optimal government spending in a New Keynesian model with labour income taxation and finds that publicspending-to-income ratio falls short of its first best level. Klein et al. (2008) study the provision of public spending in a Real Business Cycle model with labour income taxation when the policy-maker may or may not be able to commit to future policies. They find that the optimal share of public-spending-to-income is higher under commitment. Michaillat \& 
Saez (2015) find in a Real Business Cycle model with frictional unemployment that optimal government spending should exceed its first best level in order to reduce unemployment. Compared to this literature, we extend the theory of optimal public expenditure by studying the role of consumption taxation in shaping the provision of public good.

The paper is organized as follows. Section 2 sets up the model. Section 3 presents the policy analysis. Finally, Section 4 concludes.

\section{Model}

We present a discrete time, flexible price economy, with linear technology in labour, without uncertainty nor capital accumulation, where firms have monopolistic power. The benevolent government finances an endogenously determined level of government spending, $g_{t}$, through a proportional labour income tax, $\tau_{t}^{h} \in(-\infty, 1)$, a linear consumption tax, $\tau_{t}^{c} \in(-1, \infty)$, and by issuing a one-period discount bond, $b_{t+1}$. Its budget constraint is

$$
g_{t}+b_{t}=\tau_{t}^{c} c_{t}+\tau_{t}^{h} w_{t} h_{t}+p_{t}^{b} b_{t+1}
$$

where $c_{t}$ is private consumption, $w_{t}$ are real wages, $h_{t}$ represents labour supply and $p_{t}^{b}$ is the ex-ante real bond price. We consider two versions of the model: The first version allows only for labour income taxation and debt, while the second version allows only for consumption taxation and debt. In this way we can fully disentangle the relative merits and inefficiencies associated with each tax instrument. While we describe the model with all of these fiscal instruments, it should be understood that a subset of them are set to zero in any version of the model.

The representative household takes prices and policies as given, chooses consumption, savings via public bond holding, $b_{t+1}$, and leisure $\ell_{t}$, with the standard time constraint, $1=h_{t}+\ell_{t}$, in order to maximise the discounted value of her lifetime utility, i.e.

$$
\max _{c_{t}, \ell_{t}, b_{t+1}} \sum_{t=0}^{\infty} \beta^{t} u\left(c_{t}, \ell_{t}, g_{t}\right),
$$

where $\beta \in(0,1)$ is the discount factor. The utility function in (2) is separable across time, twice continuously differentiable, with a constant Frisch elasticity of labour supply. 
Furthermore we assume that utility is increasing in its three arguments, that is $u_{c, t}>0$, $u_{\ell, t}>0$ and $u_{g, t}>0$, concave, i.e. $u_{c c, t}<0, u_{\ell \ell, t}<0$ and $u_{g g, t}<0$, and that allows for non-separability between leisure and consumption and complementarity/substitutability between private and public spending. We indicate respectively with $u_{x, t}$ and $u_{x x, t}$ the first and the second partial derivatives of $u_{t}$ with respect to the generic variable $x$ at time $t$.

Consistently with these properties, we specify the per-period utility function as,

$$
u\left(c_{t}, \ell_{t}, g_{t}\right)=\left\{\begin{array}{l}
\frac{\left(c_{t}^{\alpha} g_{t}^{1-\alpha}\right)^{1-\sigma}\left(1-\kappa(1-\sigma)\left(1-\ell_{t}\right)^{1+1 / \varphi}\right)^{\sigma}-1}{1-\sigma}, \text { for } \sigma \neq 1, \\
\alpha \log \left(c_{t}\right)+(1-\alpha) \log \left(g_{t}\right)-\kappa\left(1-\ell_{t}\right)^{1+1 / \varphi}, \text { for } \sigma=1,
\end{array}\right.
$$

where $\alpha \in[0,1]$ represents the relative utility weight on private consumption, $\varphi$ is the (constant) Frisch elasticity of labour supply, $\kappa$ is the utility weight of leisure and $\sigma$ is the elasticity of intertemporal substitution (EIS) and the relative risk aversion parameter. From (3) it follows that $u_{c g}$ is $\left\langle(>,=) 0\right.$ if and only if $\sigma$ is $>(<,=) 1 .^{2}$ The latter condition means that when the current-period utility function $u($.$) exhibits strong (weak) curvature, c$ and $g$ are Edgeworth substitutes (complements), see Ni (1995).

Both private and public consumption baskets consist of constant-elasticity of substitution aggregators of individual goods $i$, i.e. $c_{t}=\left(\int_{0}^{1} c_{i t^{\frac{\epsilon-1}{\epsilon}}} d i\right)^{\frac{\epsilon}{\epsilon-1}}$ and $g_{t}=\left(\int_{0}^{1} g_{i t^{\frac{\epsilon-1}{\epsilon}}}^{\frac{\epsilon}{\epsilon}}\right)^{\frac{\epsilon}{\epsilon-1}}$, where $\epsilon>1$ is the elasticity of substitution. The household's budget constraint can be written as

$$
\left(1+\tau_{t}^{c}\right) c_{t}+p_{t}^{b} b_{t+1}=w_{t}\left(1-\ell_{t}\right)\left(1-\tau_{t}^{h}\right)+b_{t}+d_{t}, \quad \forall t,
$$

where $d_{t}$ are the aggregate profits rebated from the monopolistic competitive producers. The household's optimal behaviour is characterised by the following first order conditions

$$
\frac{u_{\ell, t}}{u_{c, t}}=w_{t} \frac{\left(1-\tau_{t}^{h}\right)}{\left(1+\tau_{t}^{c}\right)}, \quad \forall t
$$

and

$$
p_{t}^{b}=\beta \frac{u_{c, t+1}\left(1+\tau_{t}^{c}\right)}{u_{c, t}\left(1+\tau_{t+1}^{c}\right)}, \quad \forall t .
$$

Examining the household's first-order conditions, the different distortions caused by the two tax instruments become apparent. The labour income tax distorts the (intratemporal) 
consumption-leisure margin, (5). The current consumption tax distorts the same margin. In addition, both the current and next period's consumption tax enter into the current (forward-looking) Euler equation, (6).

We now present the supply side of the economy. Each of the differentiated goods $i \in$ $[0,1]$ is produced by one monopolistic firm who employs labour using a linear production technology $y_{i, t}=h_{i, t}$, where $y_{i, t}$ is the output of the generic firm $i$. Via standard optimality conditions, one can show that the marginal costs for firm $i$ are simply equal to the real wages $w_{t}$. Monopolistic competition implies that firms can charge a price higher than their marginal costs. Normalising prices to 1 , this implies $\mu_{i} w_{t}=1$, where $\mu_{i}=\frac{\epsilon}{\epsilon-1} \geq 1$ represents the (time-invariant) mark-up of firms $i$ over their marginal costs. Finally, firm's $i$ profits are equal to $d_{i, t}=\left(1-w_{t}\right) y_{i, t}=\frac{1}{\epsilon} y_{i, t}$. Note that under perfect competition $(\epsilon \rightarrow \infty)$ profits will be zero. We concentrate on symmetric equilibrium. Thus the following aggregations hold for any $i, 1) h_{i, t}=h_{t}$;2) $\left.y_{i, t}=y_{t} ; 3\right) \mu_{i, t}=\mu_{t}$; and 4) $d_{i, t}=d_{t}$. We are now ready to provide a formal definition of the decentralised equilibrium.

Definition 1 (Decentralised Equilibrium). A decentralised equilibrium consists of government policies, $\left\{\tau_{t}^{h}, \tau_{t}^{c}, g_{t}, b_{t+1}\right\}_{t=1}^{\infty}$, prices, $\left\{w_{t}, p_{t}^{b}\right\}_{t=1}^{\infty}$, and private sector allocations, $\left\{c_{t}, \ell_{t}, h_{t}, y_{t}, d_{t}\right\}_{t=1}^{\infty}$, satisfying, the government's budget constraint, (1); the private sector optimisation taking government policies and prices as given, that is, the household's time constraint, $\ell_{t}+h_{t}=1$, the household's budget constraint, (4), and optimality conditions, (5), (6); the market clearing condition, $c_{t}+g_{t}=y_{t}$; the transversality condition $\lim _{T \rightarrow \infty} \beta^{T} \frac{u_{c, T}}{1+\tau_{T}^{c}} b_{T}=0$ and the no-Ponzi game condition $\lim _{T \rightarrow \infty}\left[\left(\prod_{i=0}^{T-1} p_{i}^{b}\right) b_{T}\right]=0$, taking the initial level of debt $b_{0}$ as given.

\section{Ramsey Policy}

Our policy exercise starts by defining the efficient allocation of the model.

Definition 2 (First Best). The Social Planner's Program defines the first-best allocation. This consists of allocations $\left\{g_{t}, c_{t}, \ell_{t}, h_{t}, y_{t}\right\}_{t=0}^{\infty}$ that maximise (2) subject to the household's 
time constraint, $1=h_{t}+\ell_{t}$, the production function, $y_{t}=h_{t}$, and the market clearing condition, $c_{t}+g_{t}=y_{t}$.

Proposition 1 (Social Planner's Problem). The Social Planner's allocation is

$$
u_{c, t}^{s p}=u_{g, t}^{s p}=u_{\ell, t}^{s p}, \quad \forall t
$$

Proof. The proof is straightforward. First let us substitute the production function into the market clearing condition to eliminate $y_{t}$ and have a single constraint to the maximisation problem. Then by taking the first order conditions and combining them through the Lagrangian multiplier, we obtain (7).

A variable with the superfix ${ }^{s p}$ indicates its level in the Social Planner (or first-best) allocation. Consistent with the seminal theory of optimal public expenditure presented in Samuelson (1954), in the first-best equilibrium the marginal utilities of private and public consumption must equate the marginal utility of leisure. This simple allocation rule is optimal because it is equally costly to produce public and private consumption goods. ${ }^{3}$

Definition 3 (Ramsey Problem). The Ramsey policy-maker maximises (2) over the decentralised equilibria. A Ramsey outcome is a decentralised allocation that attains the maximum of (2).

Compared to the Social Planner, the Ramsey Planner faces three inefficiencies. First, the Planner has to balance its budget by using distortive taxation, which means that the government has to sacrifice resources in order to finance its expenditure. Second, the presence of monopolistic competition creates, via the real wages, an inefficient wedge between the marginal utility of leisure and the marginal utility of consumption. This generates a shortage in the supply of labour. Third, the Planner has to deal with the burden of a positive level of debt, which increases the government financing needs, further deteriorates resources and creates a time inconsistency problem. Our exercise aims to study how the Ramsey policymaker trades off these inefficiencies in order to maximise welfare. 
We will now present the policy problems for different fiscal financing schemes, i.e. labour income vs. consumption taxation. Following the literature, e.g. Lucas \& Stokey (1983), we adopt a primal approach, meaning that we express the policy problems in terms of allocations rather than tax rates.

Labour Income Taxation. In the model with solely labour income taxes, i.e. $\tau_{t}^{c}=0 \forall t$, for a given initial level of debt $\left(b_{0}\right)$, the Ramsey Planner maximises equation (2), subject to the aggregate feasibility constraint $\left(1-\ell_{t}=c_{t}+g_{t}\right)$ and the implementability constraint ${ }^{4}$

$$
u_{c, t} c_{t}+\beta u_{c, t+1} b_{t+1}=u_{\ell, t}\left(1-\ell_{t}\right)+u_{c, t} b_{t}+\frac{1}{\epsilon} u_{c, t}\left(1-\ell_{t}\right), \forall t=0,1,2, \ldots
$$

Taking derivatives to the associated Lagrangian problem, the optimality conditions are

$$
\begin{gathered}
u_{\ell, t}\left(1+\gamma_{t}\right)-\gamma_{t}\left[u_{\ell \ell, t}\left(1-\ell_{t}\right)-\frac{1}{\epsilon} u_{c, t}\right]+u_{c \ell, t}\left\{\gamma_{t}\left[c_{t}-\frac{1}{\epsilon}\left(1-\ell_{t}\right)\right]-\left(\gamma_{t}-\gamma_{t-1}\right) b_{t}\right\}=\lambda_{t} \\
u_{c, t}\left(1+\gamma_{t}\right)+\gamma_{t} u_{c c, t}\left[c_{t}-\frac{1}{\epsilon}\left(1-\ell_{t}\right)\right]-\left(\gamma_{t}-\gamma_{t-1}\right) u_{c c, t} b_{t}-\gamma_{t} u_{\ell c, t}\left(1-\ell_{t}\right)=\lambda_{t} \\
u_{g, t}+\gamma_{t}\left[u_{c g, t} c_{t}-u_{\ell g, t}\left(1-\ell_{t}\right)-u_{c g, t} b_{t}-u_{c g, t}\left(1-\ell_{t}\right) \frac{1}{\epsilon}\right]+\gamma_{t-1} u_{c g, t} b_{t}=\lambda_{t} \\
\gamma_{t+1}=\gamma_{t}, \quad \gamma_{-1}=0
\end{gathered}
$$

where $\lambda_{t} \geq 0$ and $\gamma_{t} \geq 0$ denote the Lagrangian multipliers attached to the feasibility and the implementability constraints, respectively.

Consumption Taxation. Similar to the previous case, with consumption taxes, i.e. $\tau_{t}^{h}=0$ $\forall t$, for a given initial level of debt $\left(b_{0}\right)$, the Ramsey Planner maximises equation (2), subject to the aggregate feasibility constraint $\left(1-\ell_{t}=c_{t}+g_{t}\right)$ and the implementability constraint

$$
u_{c, t} \frac{\epsilon-1}{\epsilon} c_{t}+\beta u_{\ell, t+1} b_{t+1}=u_{\ell, t}\left(1-\ell_{t}\right)+u_{\ell, t} b_{t} .
$$

Taking derivatives to the associated Lagrangian problem, the optimality conditions are

$$
\begin{gathered}
u_{g, t}+\gamma_{t} u_{c g, t} \frac{\epsilon-1}{\epsilon} c_{t}-\left(\gamma_{t}-\gamma_{t-1}\right) u_{\ell g, t} b_{t}-\gamma_{t} u_{\ell g, t}\left(1-\ell_{t}\right)=\lambda_{t} \\
u_{\ell, t}+\gamma_{t} u_{c g, t} \frac{\epsilon-1}{\epsilon} c_{t}-\left(\gamma_{t}-\gamma_{t-1}\right) u_{\ell \ell, t} b_{t}-\gamma_{t}\left(1-\ell_{t}\right) u_{\ell \ell, t}+\gamma_{t} u_{\ell, t}=\lambda_{t} \\
u_{c, t}+\gamma_{t} \frac{\epsilon-1}{\epsilon}\left(u_{c c, t} c_{t}+u_{c, t}\right)-\left(\gamma_{t}-\gamma_{t-1}\right) u_{\ell c, t} b_{t}-\gamma_{t} u_{\ell c, t}\left(1-\ell_{t}\right)=\lambda_{t}
\end{gathered}
$$




$$
\gamma_{t+1}=\gamma_{t} \quad \gamma_{-1}=0
$$

Importantly, (12) and (17) imply that $\gamma_{t}$ must be constant $\forall t \geq 1$. As presented in Lucas \& Stokey (1983), in this class of models the steady-state level of debt is not determined. Given that in the equilibrium $\gamma_{t}$ must be constant, all the remaining conditions are identical $\forall t \geq 1$, and so do the values of $c, g, \ell$, and $b$. Thus, the steady-state allocations depend on $\gamma$. Equations (10) and (16) evaluated at time 0 show that $\gamma$ depends on the initial level of debt, $b_{0}$. Hence the steady-state of the Ramsey Problem(s) depends on initial conditions.

However, under the two different tax instruments, the Ramsey Planner faces different implementability constraints, i.e. (8) versus (13). This implies that, given the same initial level of public debt $b_{0}$, and the structural parameters of the economy, the allocations along the transition and in turn the welfare properties of the two policy scenarios will be in general different. The aim of this policy exercise is to explore these differences.

\subsection{Analytical Results}

We study a version of the model where the instantaneous utility is separable in its three arguments, i.e. $\sigma=1$, see equation (3). In this case, all cross derivatives are equal to zero, e.g. $u_{c g}=0$ ( $c$ and $g$ are Edgeworth independent), and

$$
\begin{gathered}
u_{c}=\frac{\alpha}{c} ; u_{g}=\frac{1-\alpha}{g} ; u_{c c}=-\frac{\alpha}{c^{2}} ; u_{g g}=-\frac{1-\alpha}{g^{2}} ; \\
u_{\ell}=\kappa\left(1+\frac{1}{\varphi}\right)(1-\ell)^{\frac{1}{\varphi}} ; \quad u_{\ell \ell}=-\kappa\left(1+\frac{1}{\varphi}\right)\left(\frac{1}{\varphi}\right)(1-\ell)^{\frac{1}{\varphi}-1} .
\end{gathered}
$$

Given these functional forms, the first-best allocation presented in Proposition 1 specialises to

$$
\frac{1-\alpha}{g_{t}^{s p}}=\frac{\alpha}{c_{t}^{s p}}=\kappa\left(1+\frac{1}{\varphi}\right)\left(1-\ell_{t}^{s p}\right)^{\frac{1}{\varphi}}, \forall t .
$$

This model restriction is instructive as it helps to develop transparent economic intuitions through a set of analytical insights. In turn, these insights will allow us to disentangle the effects of each inefficiency (distortionary taxation, monopolistic competition and government debt) faced by the Ramsey Planner on the optimal allocations under the two fiscal financing 
schemes. We first analyse the case where the government has access only to labour income taxes.

Proposition 2 (Optimal Policy with Labour Income Taxation). Under labour income taxation, given a generic positive level of initial outstanding debt, $b_{0}$, and the conditions on the Lagrangian multiplier $\gamma_{t}$, the Ramsey allocation is described by the implementability constraint (8),

$$
\frac{1-\alpha}{g_{t}}=\kappa\left(1+\frac{1}{\varphi}\right)\left(1-\ell_{t}\right)^{1 / \varphi}\left[1+\gamma\left(1+\frac{1}{\varphi}\right)\right]+\frac{\gamma}{\epsilon} \frac{\alpha}{c_{t}}, \forall t \geq 0
$$

and

$$
\begin{cases}\frac{1-\alpha}{g_{0}}=\frac{\alpha}{c_{0}}+\frac{\gamma}{\epsilon} \frac{\alpha\left(1-\ell_{0}\right)}{c_{0}^{2}}+\frac{\alpha \gamma}{c_{0}^{2}} b_{0}, & t=0 \\ \frac{1-\alpha}{g_{t}}=\frac{\alpha}{c_{t}}+\frac{\gamma}{\epsilon} \frac{\alpha\left(1-\ell_{t}\right)}{c_{t}^{2}}, & t=1,2, \ldots\end{cases}
$$

Proof. See Appendix.

We begin the explanation of Proposition 2 by considering the simplest case of the model with labour income taxation, where debt is zero $\left(b_{t}=0 \forall t\right.$, so that $\left.\frac{\alpha \gamma}{c_{0}^{2}} b_{0}=0\right)$ and there is no monopolistic competition $\left(\epsilon \rightarrow \infty\right.$, so that $\left.\frac{\gamma}{\epsilon} \frac{\alpha}{c_{t}}=\frac{\gamma}{\epsilon} \frac{\alpha\left(1-\ell_{t}\right)}{c_{t}^{2}}=0 \forall t\right)$, i.e. where the only inefficiency is represented by distortionary taxation. First, as in (19), this inefficiency creates a wedge, $\left[1+\gamma\left(1+\frac{1}{\varphi}\right)\right] \geq 1$, between the marginal utility of government spending and the marginal utility of leisure, as labour supply and total production are reduced by distortionary taxation below their efficient levels. Second, the Ramsey allocation becomes time-invariant, i.e. the absence of public debt eliminates the time inconsistency problem of the government. As a result, equation (20) has the same elements at time 0 and for all subsequent periods. Third, equation (20) shows that the optimal steady-state ratio of public to private consumption is equal to the one chosen in the efficient allocation, i.e. $\frac{1-\alpha}{g_{t}}=\frac{\alpha}{c_{t}}$, even though labour supply is distorted by income taxation. It should be noted that this latter result does not hold in general and depends, in particular, on the utility function where the substitution and the income effects of government spending on labour supply cancel each other out. The utility function we have chosen is particularly instructive, as it 
produces the first-best choice of public to private consumption, if there are tax distortions but no monopolistic competition nor public debt. This allows to show how the introduction of these two inefficiencies changes the optimal provision of public goods.

We now add monopolistic competition $(\epsilon<\infty)$ to the previous case. First, this creates an additional wedge in (19), whose strength crucially depends on $\epsilon$, i.e. $\frac{\gamma}{\epsilon} \frac{\alpha}{c_{t}}$, and generates a further decrease in the total production, as prices now exceed marginal costs. Second, the presence of monopolistic competition introduces a new wedge between marginal utility of public and private consumption, see equation (20). This is because the inefficiency represented by untaxed profits makes, other things equal, the substitution effect of government spending on labour supply stronger than its income effect. As a result, the Ramsey planner decreases government spending (relative to private consumption) below its efficient level, i.e. $\frac{1-\alpha}{g_{t}}>\frac{\alpha}{c_{t}}$ given that $\frac{\gamma}{\epsilon} \frac{\alpha\left(1-\ell_{t}\right)}{c_{t}^{2}}>0$, thus lowering taxation and in turn shrinking the inefficient wedge between consumption and leisure.

Finally, we consider a situation with perfect competition $(\epsilon \rightarrow \infty)$ and positive initial level of public debt $\left(b_{0}>0\right)$. The presence of public debt introduces a time inconsistency problem in the Ramsey allocation, whose strength depends on the initial level of outstanding debt, i.e. $\frac{\alpha \gamma}{c_{0}^{2}} b_{0}$. As a result, equation (20) is different at time 0 and in any subsequent period. This is due to the Planner's incentive to manipulate the bond price on the initial level of debt. In a generic period $t \geq 1$, current consumption influences both bond prices at time $t$ and at $t-1$. As a consequence, if the government uses taxes and public expenditure to increase the price of the bond at time $t$, other things equal, the bond price at time $t-1$ decreases. Instead at $t=0$ consumers' savings and previous bond price are given. Therefore, if the government inherits a positive level of debt, it can benefit from an increase in the price of the bond at time 0 without incurring any additional cost. Equation (20) shows that this is implemented by increasing the ratio of private to public consumption at time 0 above its efficient level, i.e. $\frac{1-\alpha}{g_{0}}>\frac{\alpha}{c_{0}}$, where the increase is proportional to the initial level of public debt, $b_{0}$. This policy implies lower initial taxes and higher demand for saving, thus allowing the government to sell its bonds at a more convenient price. 
We now turn our attention to the case where only consumption taxation is available to the Ramsey Planner.

Proposition 3 (Optimal Policy with Consumption Taxation). Under consumption taxation, given a generic positive level of initial outstanding debt $b_{0}$ and the conditions on the Lagrangian multiplier $\gamma$, the Ramsey allocation is described by the implementability constraint $(13)$

$(i)$

$$
\begin{cases}\frac{1-\alpha}{g_{0}}=\kappa\left(1+\frac{1}{\varphi}\right)\left(1-\ell_{0}\right)^{1 / \varphi}\left[1+\gamma\left(1+\frac{1}{\varphi}\right)\right]+\gamma \kappa \frac{1}{\varphi}\left(1+\frac{1}{\varphi}\right)\left(1-\ell_{0}\right)^{1 / \varphi-1} b_{0}, & t=0 \\ \frac{1-\alpha}{g_{t}}=\kappa\left(1+\frac{1}{\varphi}\right)\left(1-\ell_{t}\right)^{1 / \varphi}\left[1+\gamma\left(1+\frac{1}{\varphi}\right)\right], & t=1,2, \ldots\end{cases}
$$

and

$$
\frac{1-\alpha}{g_{t}}=\frac{\alpha}{c_{t}} \quad \forall t \geq 0
$$

Proof. See Appendix.

With perfect competition and no public debt, the optimal allocation under consumption taxation mimics the one under labour income taxation, as the two policy problems are equivalent. ${ }^{5}$ Therefore the description presented above applies here, mutatis mutandis. Things start being different if we consider a model with monopolistic competition and no public debt. Under consumption taxation, this inefficiency affects the allocation only through the implementability constraint in (13) (via an increase in $\gamma$ ), but it does not alter the wedge between public and private consumption, which stays at the efficient level independently of $\epsilon$, see equation (22) . This result is driven by the fact that any change in monopolistic power is absorbed by consumption taxation, which acts as indirect taxation of (inefficient) profits. We call this property the intratemporal gain of consumption taxation and note that this effect is absent under labour income taxation. This efficiency gain, combined with the specification of the utility function, guarantees that for any change in consumption tax rate, triggered for instance by higher monopolistic power, the substitution and income effect of 
labour supply are of the same magnitude, thus leaving the ratio between private and public consumption constant at its first-best level.

Finally, also in the case of perfect competition and initial public debt, the Ramsey Planner keeps the ratio of public to private consumption at the first-best level, independently of $b_{0}$. This is because consumption taxation acts as a one-time, indirect taxation of the initial wealth (represented here by debt) that is inelastically supplied and therefore can be taxed without distorting the economy. The Planner uses this feature by increasing taxes at $t=0$, thus reducing the burden of public debt for any $t \geq 1$. As a result, the time inconsistency problem is less severe compared to the labour income tax case, and so is the incentive to manipulate the initial bond price and the ratio between private and public consumption. We label this property the intertemporal gain of consumption taxation. As for the intratemporal gain, the specification of the utility function guarantees that for any initial change in consumption tax rate, due to higher $b_{0}$, the substitution and income effect of labour supply are of the same magnitude, thus leaving the ratio between private and public consumption constant at its efficient level. However, due to higher taxes in $t=0$, this policy comes at the cost of a decrease in efficiency in the first period. From an analytical point of view, this

one-off wedge is represented by the term $\gamma \kappa \frac{1}{\varphi}\left(1+\frac{1}{\varphi}\right)\left(1-\ell_{0}\right)^{1 / \varphi-1} b_{0}$ in $(21)$ and increases in the initial level of debt.

Summing up, two main results emerge from this Section. First, the two fiscal financing schemes lead to fundamental differences in the dynamics of allocations and prices. Second, the intratemporal and intertemporal efficiency gains of taxing consumption imply that the optimal size of government spending is higher under consumption taxes than under labour income taxes.

\subsection{Quantitative Analysis}

We now turn to numerical methods in order to solve for the optimal fiscal policy mix under the two fiscal scenarios, i.e. consumption and labour income taxation. We will also quantify the intratemporal and intertemporal welfare gains from taxing consumption. In order to do 
so, we solve a calibrated version of our economy. In what follows we specify the benchmark calibration of the model as well as some alternative parametrisations. To this end, we need to make some further assumptions up front.

The model is calibrated at annual frequency on US data over the period 1995-2010. Data are collected from Trabandt \& Uhlig (2011). We set the discount factor, $\beta$, to 0.973. This value implies an average annual bond prices of 2.79 percent, consistent with US data for the period under consideration. For the benchmark case, we set $\sigma$ equal to 1 so that the utility is separable in its three arguments. In this way we can give a precise quantitative assessment of the analytical results discussed in Section 3.1. We then allow non-separability between public and private consumption by setting $\sigma$ either to 0.5 (Edgeworth complementarity between $g$ and $c$ ) or to 2 (Edgeworth substitutability between $g$ and $c$ ).

We calibrate the relative utility weight on private consumption, $\alpha$, such that, given the other parameters, the first-best government-spending-to-income ratio is 16.1 percent. This value implies that in the benchmark Ramsey steady state with labour income tax the ratio of government spending to GDP is 15.5 percent. This is consistent with the US data for the period under consideration. It is important to note that the Cobb-Douglas specification between private and public consumption implies that $\alpha$ pins down uniquely the expenditure shares in the first-best.

We set the elasticity of substitution among good varieties, $\epsilon$, to 6.4, which implies a price mark-up of around 15.6 percent. This value is consistent both with early empirical estimates, e.g. Rotemberg \& Woodford (1998), as well as more recent ones, e.g. Epifani \& Gancia (2011) and it lies within standard parametrisation adopted in the macroeconomic literature, see inter alia Kryvtsov \& Midrigan (2013). Given the importance of this parameter in shaping the optimal provision of public goods under the two financing scenarios, we allow this elasticity to vary between 5 and $\infty$, that correspond to a high mark-up $(\epsilon=5)$ and to the perfect competition $(\epsilon=\infty)$ cases.

In our benchmark case we fix the initial level of public debt, $b_{0}$, so that the share of debt-to-GDP is as in the US over the period of study, i.e. $b_{0} / y_{0}=\gamma_{b}=0.64$. We then solve 
for the optimal allocation for different values of debt-to-GDP ratios.

Finally, for the benchmark case of $\sigma=1$, we set the Frisch elasticity of labour supply equal to 1, a value consistent with the survey evidence of Kimball \& Shapiro (2008). The micro and macro literature tend to differ on the estimates of the Frisch elasticity. For this reason we also control the quantitative implications of our policy exercise with a wide range of values of $\varphi$. For consistency, we calibrate $\kappa$ such that, given the other structural parameters, households work 27.5 percent of their time endowment in the first best equilibrium. This value implies that in the benchmark Ramsey steady state with labour income tax, households work 25 percent of their time, a value consistent with the average labour supply found in the US data for our sample. The complete description of the parametrisation adopted is reported in Table 1.

As explained in Section 3, the Ramsey problem can be recast as a two-period problem, at $t=0$ and at $t \geq 1$, imposing the extra condition that $\gamma_{-1}=0$. By doing so, one can find the solution to the Ramsey allocation solving a system of non-linear equations and time 0 and for any $t \geq 1$, given the initial level of debt, $b_{0}$.

Table 2 reports the allocations and welfare under the benchmark calibration for the cases of labour income tax and consumption tax, as well as the efficient allocation. As explained in the analytical Section, under labour income taxes, the incentive to manipulate bonds prices translates into a decrease in the initial public spending-income ratio, which is set 2 percentage points below its long run level, and a consequent reduction in the initial level of taxes, set as low as 6.1 percent. This policy fosters the demand for saving, and allows the government to sell its bonds at a more convenient price in the first period, i.e. $p_{0}^{b}=1.071$. At the same time, lower taxes in the initial period push households to postpone leisure. As a result, income in the initial period is around 2 percentage points above its long run level. Finally and consistent with Proposition 2, the combination of monopolistic competition and initial public debt implies that the government-spending-to-income ratio is below its first best counterpart along the entire transition path.

Under consumption taxation the incentive to manipulate the initial bond prices is lower, 
as the Ramsey planner can indirectly tax the initial level of wealth via increasing taxes in the initial period. This policy reduces debt and debt-to-income ratio for any $t \geq 1$, thus lowering the need of fiscal revenues in the long run. Since the long-run debt is smaller, the time inconsistency problem under consumption taxation is less severe than under labour income taxation. Higher taxes in the initial period create an incentive to postpone labour supply and consumption. As a result, income is lower in $t=0$ than in the subsequent periods. As shown analytically in Proposition 3, under consumption taxation the government-spendingto-income ratio is at its efficient level for the entire transition path.

The policy differences between the two fiscal financing schemes imply substantial welfare gains from taxing consumption. It is interesting to note that these gains come both from the role that consumption taxation has in indirectly taxing profits, (intratemporal gains from taxing consumption) and from the dynamic properties of consumption taxation which allows to reduce debt in the long run (intertemporal gains from taxing consumption). In our benchmark calibration, despite the fact that the consumption tax base is smaller than the labour income tax base, taxing consumption rather than labour income can reduce our measure of welfare loss by 20.45 percent. $^{6}$

In Table 3 we solve the model with different degrees of monopolistic competition. ${ }^{7}$ In order to do so we vary the parameter $\epsilon$. For the high monopolistic case we set $\epsilon=5$, a value that implies a mark-up of $25 \%$. This elasticity is higher than the estimates reported in IO studies, around 3, but lower than elasticities that are consistent with estimates of mark-up from production function estimates, around 10, see Kryvtsov \& Midrigan (2013). Then we solve the model under perfect competition, i.e. $\epsilon \rightarrow \infty$. This exercise is particularly instructive as it allows to gather a better quantitative insight about the welfare gains of taxing consumption, i.e. intratemporal vs. intertemporal gains. This is because the role of consumption taxes as indirect taxation of profits disappears under perfect competition. Hence the resulting welfare gains of taxing consumption are generated only by the intertemporal dimension. In our parametrisation, the intertemporal gains of taxing consumption amount to 9.1 percent. Differently, when monopolistic power is high, i.e. $\epsilon=5$, the role of con- 
sumption taxation as an indirect taxation of profits magnifies. Hence the welfare gains from taxing consumption increases with respect to the benchmark calibration and amount to 22 percent. Moreover it is interesting to see that under labour income tax the share of government spending to total output in the initial period decreases respect to the benchmark case. As explained in Section 3.1, this is due to the negative substitution effect on labour supply generated by the increase in monopolistic competition which pushes the Ramsey planner to reduce public spending.

Table 4 presents the results from solving the model for different initial levels of public debt. By varying $b_{0}$ and keeping the monopolistic competition at its benchmark value, we can control and in turn shut down the intertemporal gains of taxing consumption. In the limiting case with no initial debt, the Ramsey problem reduces to a static maximisation problem. This case is presented in the top quadrant of Table 4. Here the gains from taxing consumption are solely given by its role in indirectly taxing profits, i.e. intratemporal gains from taxing consumption, and amount to 17.9 percent. While both the intertemporal and the intratemporal gains from taxing consumption are sizeable, the intratemporal gains are quantitatively more important.

In the second part of Table 4 we increase the initial debt equal to 120 percent of GDP, a value that is almost twice as big as in the benchmark calibration. The results follow consistently as expected. Compared to the benchmark, under both tax scenarios, the Ramsey Planner suffers greater welfare losses and has a stronger incentive to manipulate the initial bond price $p_{0}^{b}$. Moreover, as describe in Proposition 2, under labour income taxation, the higher need for fiscal revenues reinforce the substitution effect of labour supply. Compared to the benchmark case, this pushes the Ramsey planner to lower the government-spending-toincome-ratio along the entire transition path. In this case, the gains from taxing consumption amount to around 22.4 percent.

Table 5 presents the results from varying the Frisch elasticity of labour supply. We solve the model with two values that are somehow at the extremes of the available estimates of the elasticity of labour supply. In particular, we consider (i) $\varphi=0.2$, which is in line with recent 
micro estimates such as Domeij \& Floden (2006) (see also Guner et al. , 2012), and (ii) $\varphi=5$ as a high value, which is sometimes chosen to better match the intertemporal variation of aggregate hours (e.g. Galí et al. , 2007). We adjust $\kappa$ appropriately in each case as described for the benchmark parametrisation. When the Frisch elasticity is low, i.e. $\varphi=0.5$, the substitution effect of labour supply is reduced. Thus the policy-maker can sustain the same level of public expenditure and debt at a lower welfare cost. Under labour income tax this implies that the Ramsey Planner can afford to push the public spending-income ratio closer to the first best level without distorting excessively the economy. Of course this result is reversed when the Frisch elasticity of high i.e. $\varphi=5$ as the substitution effect of labour supply gets bigger. As in the case of labour income taxation, under consumption taxation, the economy is facing higher welfare losses when the Frisch elasticity is high compared to when is low. The gains from taxing consumption decrease slightly as the Frisch elasticity increases, passing from 20.7 percent $(\varphi=0.5)$ to 20 percent $(\varphi=5)$.

Table 6 presents the allocation and welfare under the alternative parametrisation where $\sigma \neq 1$. As for the previous case, we re-calibrate $\kappa$ so that in the efficient allocation $\ell^{s p}=0.725$. We keep all the remaining parameters at their benchmark values. The parameter $\sigma$ controls both the Elasticity of Intertemporal Substitution (EIS) and the complementarity/substitutability between private and public consumption. Therefore in setting this parameter we follow the literature that estimates the EIS as well as the evidence presented in Ni (1995). There is not a unanimous consensus on the EIS. To this end, we solve the model with $\sigma=2$, which is consistent with low values of EIS as typically found by the micro literature, see among others Blundell et al. (1994). This value also implies that private and public consumption are Edgeworth substitutes. ${ }^{8}$ We also solve the model with $\sigma=0.5$, a number consistent with some macro-finance literature that finds high EIS, see among others Bansal \& Yaron (2004). This value implies that private and public consumption are Edgeworth complements. Given this parametrisation, the utility function is not longer separable in its three elements, meaning that labour supply decisions directly affect the marginal utility of private and public consumption, and vice versa. 
Despite this, the main message from this experiment is similar both qualitatively and quantitatively to the benchmark case. However there are some noticeable differences. We start describing the situation with labour income taxes, low EIS and gross substitutability between private and public consumption, i.e. $\sigma=2$. On the one hand, with low EIS, it is harder for the Planner to redistribute private consumption intertemporally. Compared to the benchmark case, this effect pushes the policy-maker to reduce even further taxation in the initial period and sell bonds at a more favourable price, i.e. $p_{0}^{b}$ is bigger when $\sigma=2$ than in the benchmark case. On the other hand, substitutability between private and public consumption, i.e. $u_{c g}<0$, implies that the planner can decrease strategically government spending in the initial period in order to sustain a higher level of consumption. However, from our numerical simulation, it appears that this latter effect is weaker than the EIS channel.

Differently, under consumption taxation the Ramsey planner has a weaker incentive to manipulate the initial bond prices compared with the benchmark case. This is because the policy-maker can now influence directly the Euler equation via a dynamic pattern of consumption taxes in period zero and in subsequent periods. As a result, the increase in taxes in the initial period and the subsequent effect on bond prices are less dramatic than the benchmark case.

As in the the case with separable preferences, under consumption taxation, the Ramsey planner sets the share of government spending as in the first-best allocation, while under labour income taxes, the optimal share of government spending falls short of its first-best counterpart along the entire transition path. ${ }^{9}$ The intuition for this result follows directly from the the case analysed in Section 3.1 and we therefore remind the reader to the discussion presented there. All in all, under both fiscal scenarios the welfare losses are higher than in the benchmark case. This is mainly due to the higher level of long-run public debt. In this case, the gains from taxing consumption amount to 20 percent.

Consistently, all these results are reversed when the model is solved with a high EIS and gross complementarity between private and public consumption, i.e. $\sigma=0.5$. Under 
both fiscal scenarios, the long run level of public debt is lower than in the benchmark case, leading to smaller welfare losses. The welfare gains from taxing consumption amount to 21.9 percent.

\section{Concluding Remarks}

Consumption taxation has been widely used by governments around the globe as a source of fiscal revenues. For example, as of July 2017, the value-added tax on standard items ranges from 17 (Luxembourg) to 27 (Hungary) percent in European Union countries. At the same time, government spending as a share of GDP has raised substantially to respond to an increasing need for social insurance spending on health care and retirement. In this paper we study the properties and relative merits of consumption taxation and its role in sustaining public spending by considering a simple economy characterised by infinitely lived representative households with love for public goods, a perfect competitive labour market and a monopolistic competitive goods market. In this general environment, our analysis shows that taxing consumption, compared to taxing labour income, allows the policy-maker to sustain both higher public spending and higher aggregate welfare. We are able to disentangle two effects through which consumption taxation overtake income taxes. First, consumption taxation serves as an indirect taxation of the inefficient profits produced by the non competitive good markets. This beneficial effect reduces the inefficient allocation of firms' market power and disappears under perfect competition. Second, consumption taxation acts as indirect taxation on the initial level of wealth, that is inelastically supplied, and can therefore be taxed without distorting the economy. Given that all wealth is held through public debt bonds, this one-time consumption tax reduces public debt in the long run and in turn the time-inconsistency problem of Ramsey policy making. In an economy calibrated to replicate some salient features of the US economy, we find that both effects are quantitatively important for households' welfare. 


\section{A PROOFS}

\section{A.1 PROOF OF PROPOSITION 2}

For the case of labour income taxation and $\sigma=1$, i.e. log-utility, the FOC wrt government spending (11) specialises to

$$
\frac{1-\alpha}{g_{t}}=\lambda_{t}, \forall t
$$

From this, the FOC wrt to leisure can be written as

$$
\kappa\left(1+\frac{1}{\varphi}\right)\left(1-\ell_{t}\right)^{\frac{1}{\varphi}}(1+\gamma)+\gamma\left[\kappa\left(1+\frac{1}{\varphi}\right)\left(\frac{1}{\varphi}\right)\left(1-\ell_{t}\right)^{\frac{1}{\varphi}}+\frac{1}{\epsilon} \frac{\alpha}{c_{t}}\right]=\frac{1-\alpha}{g_{t}}, \forall t \geq 0 .
$$

Rearranging terms and collecting $\kappa(1+1 / \varphi)(1-\ell)^{1 / \varphi}$, it yields

$$
\kappa\left(1+\frac{1}{\varphi}\right)(1-\ell)^{\frac{1}{\varphi}}\left[1+\gamma\left(1+\frac{1}{\varphi}\right)\right]+\frac{\gamma}{\epsilon} \frac{\alpha}{c_{t}}=\frac{1-\alpha}{g_{t}}, \forall t \geq 0 .
$$

While the FOC wrt private consumption is different at time 0 and at any future period, i.e.

$$
\frac{\alpha}{c_{0}}(1+\gamma)+\gamma\left(-\frac{\alpha}{c_{0}^{2}}\right)\left[c_{0}-\frac{1}{\epsilon}\left(1-\ell_{0}\right)\right]+\gamma \frac{\alpha}{c_{0}^{2}} b_{0}=\frac{1-\alpha}{g_{0}}, \text { for } t=0
$$

and

$$
\frac{\alpha}{c_{t}}(1+\gamma)+\gamma\left(-\frac{\alpha}{c_{t}^{2}}\right)\left[c_{t}-\frac{1}{\epsilon}\left(1-\ell_{t}\right)\right]=\frac{1-\alpha}{g_{t}}, \text { for } t \geq 1
$$

Collecting terms,

$$
\begin{aligned}
\frac{\alpha}{c_{0}}+\frac{\gamma}{\epsilon} \frac{\alpha\left(1-\ell_{0}\right)}{c_{0}^{2}}+\gamma \frac{\alpha}{c_{0}^{2}} b_{0} & =\frac{1-\alpha}{g_{0}}, \text { for } t=0 \\
\frac{\alpha}{c_{t}}+\frac{\gamma}{\epsilon} \frac{\alpha\left(1-\ell_{t}\right)}{c_{t}^{2}} & =\frac{1-\alpha}{g_{t}}, \text { for } t \geq 1
\end{aligned}
$$

QED.

\section{A.2 PROOF OF PROPOSITION 3}

For the case of consumption taxation, the FOC wrt to government spending collapses to

$$
\frac{1-\alpha}{g_{t}}=\lambda_{t}, \forall t \geq 0
$$

While the FOC wrt to private consumption can be written as

$$
\frac{\alpha}{c_{t}}+\gamma \frac{\epsilon-1}{\epsilon}\left(-\frac{\alpha}{c_{t}^{2}} c_{t}+\frac{\alpha}{c_{t}}\right)=\frac{1-\alpha}{g_{t}}, \forall t \geq 0
$$

Noting that the terms in brackets sum to 0 , the latter collapses to

$$
\frac{\alpha}{c_{t}}=\frac{1-\alpha}{g_{t}}, \forall t \geq 0
$$


The FOC wrt to leisure is in general different at time 0 and at any future date, i.e.

$$
\begin{aligned}
& \kappa\left(1+\frac{1}{\varphi}\right)\left(1-\ell_{0}\right)^{\frac{1}{\varphi}}+\gamma \kappa\left(1+\frac{1}{\varphi}\right)\left(\frac{1}{\varphi}\right)\left(1-\ell_{0}\right)^{\frac{1}{\varphi}-1} b_{0}+\gamma \kappa\left(1+\frac{1}{\varphi}\right)\left(\frac{1}{\varphi}\right)\left(1-\ell_{0}\right)^{\frac{1}{\varphi}}+ \\
+ & \gamma \kappa\left(1+\frac{1}{\varphi}\right)\left(1-\ell_{0}\right)^{\frac{1}{\varphi}}=\frac{1-\alpha}{g_{0}}, \text { for } t=0 . \\
& \kappa\left(1+\frac{1}{\varphi}\right)\left(1-\ell_{t}\right)^{\frac{1}{\varphi}}+\gamma \kappa\left(1+\frac{1}{\varphi}\right)\left(\frac{1}{\varphi}\right)\left(1-\ell_{t}\right)^{\frac{1}{\varphi}}+\gamma \kappa\left(1+\frac{1}{\varphi}\right)\left(1-\ell_{t}\right)^{\frac{1}{\varphi}}=\frac{1-\alpha}{g_{t}}, \text { for } t \geq 1 .
\end{aligned}
$$

Collecting terms, the latter can be rewritten as

$$
\begin{gathered}
\kappa\left(1+\frac{1}{\varphi}\right)\left(1-\ell_{0}\right)^{\frac{1}{\varphi}}\left[1+\gamma\left(1+\frac{1}{\varphi}\right)\right]+\gamma \kappa\left(1+\frac{1}{\varphi}\right)\left(\frac{1}{\varphi}\right)\left(1-\ell_{0}\right)^{\frac{1}{\varphi}-1} b_{0}=\frac{1-\alpha}{g_{0}}, \text { for } t=0 \\
\kappa\left(1+\frac{1}{\varphi}\right)\left(1-\ell_{t}\right)^{\frac{1}{\varphi}}\left[1+\gamma\left(1+\frac{1}{\varphi}\right)\right]=\frac{1-\alpha}{g_{t}}, \text { for } t \geq 1
\end{gathered}
$$

QED

\section{References}

Adam, Klaus. 2011. Government debt and optimal monetary and fiscal policy. European Economic Review, 55(1), 57-74.

Altig, David, Auerbach, Alan J., Koltikoff, Laurence J., Smetters, Kent A., \& Walliser, Jan. 2001. Simulating Fundamental Tax Reform in the United States. American Economic Review, 91(3), 574-595.

Auerbach, Alan J., Kotlikoff, Laurence J., \& Skinner, Jonathan. 1983. The Efficiency Gains from Dynamic Tax Reform. International Economic Review, 24(1), pp. 81-100.

Bansal, Ravi, \& Yaron, Amir. 2004. Risks for the Long Run: A Potential Resolution of Asset Pricing Puzzles. The Journal of Finance, 59(4), 1481-1509.

Blundell, Richard, Browning, Martin, \& Meghir, Costas. 1994. Consumer Demand and the Life-Cycle Allocation of Household Expenditures. Review of Economic Studies, 61(1), 57-80. 
Coleman, Wilbur John II. 2000. Welfare and Optimum Dynamic Taxation of Consumption and Income. Journal of Public Economics, 76(1), 1-39.

Correia, Isabel. 2010. Consumption Taxes and Redistribution. American Economic Review, 100(4), 1673-94.

Correia, Isabel, Farhi, Emmanuel, Nicolini, Juan Pablo, \& Teles, Pedro. 2013. Unconventional Fiscal Policy at the Zero Bound. American Economic Review, 103(4), 1172-1211.

Domeij, David, \& Floden, Martin. 2006. The Labor-Supply Elasticity and Borrowing Constraints: Why Estimates are Biased. Review of Economic Dynamics, 9(2), 242-262.

Epifani, Paolo, \& Gancia, Gino. 2011. Trade, markup heterogeneity and misallocations. Journal of International Economics, 83(1), 1 - 13.

Farhi, Emmanuel, Gopinath, Gita, \& Itskhoki, Oleg. 2014. Fiscal Devaluations. Review of Economic Studies, 81(2), 725-760.

Galí, Jordi, López-Salido, J. David, \& Vallés, Javier. 2007. Understanding the Effects of Government Spending on Consumption. Journal of the European Economic Association, $5(1), 227-270$.

Guner, Nezih, Kaygusuz, Remzi, \& Ventura, Gustavo. 2012. Taxation and Household Labour Supply. Review of Economic Studies, 79(3), 1113-1149.

Jones, Larry E., Manuelli, Rodolfo E., \& Rossi, Peter E. 1993. Optimal Taxation in Models of Endogenous Growth. Journal of Political Economy, 101(3), pp. 485-517.

Kimball, Miles S., \& Shapiro, Matthew D. 2008 (July). Labor Supply: Are the Income and Substitution Effects Both Large or Both Small? Working Paper 14208. National Bureau of Economic Research.

Klein, Paul, Krusell, Per, \& Ríos-Rull, José-Víctor. 2008. Time-Consistent Public Policy. Review of Economic Studies, 75(3), 789-808. 
Kryvtsov, Oleksiy, \& Midrigan, Virgiliu. 2013. Inventories, Markups, and Real Rigidities in Menu Cost Models. Review of Economic Studies, 80(1), 249-276.

Lucas, Robert Jr., \& Stokey, Nancy L. 1983. Optimal fiscal and monetary policy in an economy without capital. Journal of Monetary Economics, 12(1), 55-93.

Michaillat, Pascal, \& Saez, Emmanuel. 2015 (July). The Optimal Use of Government Purchases for Stabilization. Working Paper 21322. National Bureau of Economic Research.

$\mathrm{Ni}$, Shawn. 1995. An empirical analysis on the substitutability between private consumption and government purchases. Journal of Monetary Economics, 36(3), 593 - 605.

OECD. 2014. Consumption Tax Trends 2014. OECD Policy Notes, 80(2).

Ramsey, F. P. 1927. A Contribution to the Theory of Taxation. The Economic Journal, 37(145), 47-61.

Rotemberg, Julio J., \& Woodford, Michael. 1998 (May). An Optimization-Based Econometric Framework for the Evaluation of Monetary Policy: Expanded Version. Working Paper 233. National Bureau of Economic Research.

Samuelson, Paul A. 1954. The Pure Theory of Public Expenditure. The Review of Economics and Statistics, 36(4), 387-389.

Trabandt, Mathias, \& Uhlig, Harald. 2011. The Laffer curve revisited. Journal of Monetary Economics, 58(4), 305-327. 


\section{Notes}

${ }^{1}$ The most notable exception is represented by the US, although most states within the US employ some form of retail sales tax. Moreover, there have been repeated attempts to introduce a Federal Consumption Tax. For example, in January 2005, the US President George W. Bush commissioned a panel to propose a comprehensive reform to the tax code (President's Advisory Panel on Federal Tax Reform, 2005, available at http://govinfo.library.unt.edu/taxreformpanel/index-2.html). The proposal consisted in replacing the entire income-tax system with a national sales tax. However, the disagreement among panel members regarding the effects of such a reform inhibited its adoption.

${ }^{2}$ We indicate with $u_{x y, t}$ the cross derivative of the generic variables $x$ and $y$ at time $t$.

${ }^{3}$ Given that we consider homothetic preferences, the formula in (7) determines a unique efficient ratio of public-to-private consumption, $g^{s p} / c^{s p}$. As $\frac{g}{y} \equiv \frac{g / c}{g / c+1}$, equation (7) also defines a unique government purchases-output ratio, denoted by $g^{s p} / y^{s p}$.

${ }^{4}$ The implementability constraint (8) is obtained by substituting into (4) taxes and real wages via (5) and bond prices via (6) and then imposing $\tau_{t}^{c}=0$.

${ }^{5}$ In this case, equations (8), (19) and (20) are equivalent to (13), (21) and (22), respectively.

${ }^{6}$ Welfare is calculated in the following way. Let $\left\{c_{t}^{s p}, \ell_{t}^{s p}, g_{t}^{s p}\right\}_{t=0}^{\infty}$ be the allocation in the efficient equilibrium and $\left\{c_{t}^{i}, \ell_{t}^{i}, g_{t}^{i}\right\}_{t=0}^{\infty}$ the allocation under the generic policy $i$. The last row in Table 2 reports the percentage increase in consumption $v$ making the utility in the first best allocation equivalent to the alternative utility under policy $i$, i.e.

$$
\sum_{t=0}^{\infty} \beta^{t} u\left(c_{t}^{i} *\left(1+v^{i}\right), \ell_{t}^{i}, g_{t}^{i}\right)=\sum_{t=0}^{\infty} \beta^{t} u\left(c_{t}^{s p}, \ell_{t}^{s p}, g_{t}^{s p}\right),
$$

while the welfare gains of taxing consumption is given by $\left(1-v^{c t} / v^{h t}\right)$, where $v^{h t}$ and $v^{c t}$ are the consumption equivalent welfare losses under labour income and consumption taxation, respectively.

${ }^{7}$ Along the robustness analysis, for brevity reasons, we use the $\log$ specification of the utility function. In an Online Appendix available at this https://sites.google.com/site/raffaelerossiwebpage/Home/research, we solve the model with several other combinations of parameters.

${ }^{8} \mathrm{Ni}$ (1995) (Table 3, page 603) finds values of $\sigma$ both above and below 1 . The difference crucially depends on the treatment of the underlying net-of-tax real interest rate.

${ }^{9}$ This can also be shown analytically. See the Online Appendix for a detailed derivation of the optimal provision of public spending with non-separable preferences. 


\section{List of Tables}

1 Calibrated Parameters . . . . . . . . . . . . . . . . 28

2 Tax Rates and Allocations, Benchmark Case . . . . . . . . . . . . . . 29

3 Tax Rates and Allocations, Monopolistic Power . . . . . . . . . . . . . 30

4 Tax Rates and Allocations, Public Debt . . . . . . . . . . . . . . . 31

5 Tax Rates and Allocations, Frisch Elasticity . . . . . . . . . . . . . . 32

6 Tax Rates and Allocations, Non-Separable Preferences . . . . . . . . . . 33 
Table 1: Calibrated Parameters

\begin{tabular}{c|c|c|l|l} 
Parameter & Benchmark & Alternative & Description & Restriction \\
\hline$\beta$ & 0.973 & - & Discount Factor & US Data (1995-2010) \\
$\sigma$ & 1 & $0.8-2$ & EIS-Edgeworth Parameter & Literature \\
$\varphi$ & 1 & $0.2-5$ & Frisch Elasticity & Literature \\
$\kappa$ & 6.612 & Various & Weight on Leisure & US Data (1995-2010) \\
$\alpha$ & 0.839 & - & Weight on Private Consumption & US Data (1995-2010) \\
$\epsilon$ & 6.4 & $5-\infty$ & Elasticity of Substitution & US Data (1995-2010) \\
$\gamma_{b}$ & 0.640 & $0-1.2$ & Debt-to-GDP Ratio & US Data (1995-2010) \\
\hline
\end{tabular}


Table 2: Tax Rates and Allocations, Benchmark Case

\begin{tabular}{l|c|c|c|c|c} 
& First Best & \multicolumn{2}{|c|}{ Labour Income Tax } & \multicolumn{2}{c}{ Consumption Tax } \\
Variable & & $t=0$ & $t \geq 1$ & $t=0$ & $t \geq 1$ \\
\hline Consumption tax rate & - & 0 & 0 & 0.324 & 0.208 \\
Labour income tax rate & - & 0.061 & 0.207 & 0 & 0 \\
\hline Hours worked, Income & 0.275 & 0.241 & 0.224 & 0.219 & 0.230 \\
Leisure & 0.725 & 0.759 & 0.776 & 0.780 & 0.770 \\
Consumption & 0.231 & 0.233 & 0.211 & 0.184 & 0.193 \\
Public spending & 0.044 & 0.032 & 0.035 & 0.035 & 0.037 \\
Public debt & - & 0.154 & 0.163 & 0.140 & 0.114 \\
Public Debt Price & - & 1.071 & 0.973 & 1.019 & 0.973 \\
\hline Consumption-income ratio & 0.839 & 0.865 & 0.845 & 0.839 & 0.839 \\
Public spending-income ratio & 0.161 & 0.135 & 0.155 & 0.161 & 0.161 \\
Public debt-income ratio & - & 0.640 & 0.726 & 0.640 & 0.496 \\
\hline Welfare-eq. consumption loss & 0 & \multicolumn{2}{|c|}{0.044} & \multicolumn{2}{|c}{0.035}
\end{tabular}


Table 3: Tax Rates and Allocations, Monopolistic Power

\begin{tabular}{l|c|c|c|c|c} 
& First Best & \multicolumn{2}{|c|}{ Labour Income Tax } & \multicolumn{2}{c}{ Consumption Tax } \\
Variable & & $t=0$ & $t \geq 1$ & $t=0$ & $t \geq 1$ \\
\hline$\underline{\epsilon \rightarrow \infty}, \kappa=6.612$ & & & & & \\
Consumption tax rate & - & 0 & 0 & 0.278 & 0.210 \\
Labour income tax rate & - & 0.112 & 0.180 & 0 & 0 \\
Hours worked, Income & 0.275 & 0.257 & 0.249 & 0.243 & 0.250 \\
Leisure & 0.725 & 0.742 & 0.751 & 0.757 & 0.750 \\
Consumption & 0.231 & 0.219 & 0.209 & 0.204 & 0.210 \\
Government Spending & 0.044 & 0.039 & 0.040 & 0.039 & 0.040 \\
Public debt & - & 0.165 & 0.172 & 0.156 & 0.138 \\
Public debt price & - & 1.018 & 0.973 & 0.999 & 0.973 \\
Consumption-income ratio & 0.839 & 0.849 & 0.839 & 0.839 & 0.839 \\
Public spending-income ratio & 0.161 & 0.151 & 0.161 & 0.161 & 0.161 \\
Public debt-income ratio & - & 0.640 & 0.689 & 0.640 & 0.554 \\
Welfare-eq. consumption loss & 0 & & 0.011 & & 0.010 \\
\hline$\epsilon=5, \kappa=6.612$ & & & & & \\
Consumption tax rate & - & 0 & 0 & 0.338 & 0.207 \\
Labour income tax rate & - & 0.042 & 0.215 & 0 & 0 \\
Hours worked, Income & 0.275 & 0.236 & 0.217 & 0.213 & 0.224 \\
Leisure & 0.725 & 0.764 & 0.783 & 0.787 & 0.776 \\
Consumption & 0.231 & 0.206 & 0.184 & 0.178 & 0.188 \\
Government Spending & 0.044 & 0.030 & 0.033 & 0.034 & 0.036 \\
Public debt & - & 0.151 & 0.160 & 0.136 & 0.107 \\
Public debt price & - & 1.089 & 0.973 & 1.024 & 0.973 \\
Consumption-income ratio & 0.839 & 0.871 & 0.848 & 0.839 & 0.839 \\
Public spending-income ratio & 0.161 & 0.129 & 0.152 & 0.161 & 0.161 \\
Public debt-income ratio & - & 0.640 & 0.736 & 0.640 & 0.480 \\
Welfare-eq. consumption loss & 0 & & 0.059 & & 0.046 \\
\hline & & & & &
\end{tabular}


Table 4: Tax Rates and Allocations, Public Debt

\begin{tabular}{l|c|c|c|c|c} 
& First Best & \multicolumn{2}{|c|}{ Labour Income Tax } & \multicolumn{2}{c}{ Consumption Tax } \\
Variable & & $t=0$ & $t \geq 1$ & $t=0$ & $t \geq 1$ \\
\hline$\gamma_{b}=0, \kappa=6.612$ & & & & & \\
\hline Consumption tax rate & - & 0 & 0 & 0.192 & 0.192 \\
Labour income tax rate & - & 0.184 & 0.184 & 0 & 0 \\
Hours worked, Income & 0.275 & 0.227 & 0.227 & 0.231 & 0.231 \\
Leisure & 0.725 & 0.773 & 0.773 & 0.769 & 0.769 \\
Consumption & 0.231 & 0.192 & 0.192 & 0.194 & 0.194 \\
Government Spending & 0.044 & 0.035 & 0.035 & 0.037 & 0.037 \\
Public debt & - & 0 & 0 & 0 & 0 \\
Public debt price & - & - & - & - & - \\
Consumption-income ratio & 0.839 & 0.845 & 0.845 & 0.839 & 0.839 \\
Public spending-income ratio & 0.161 & 0.155 & 0.155 & 0.161 & 0.161 \\
Public debt-income ratio & - & 0 & 0 & 0 & 0 \\
Welfare-eq. consumption loss & 0 & & 0.039 & & 0.032 \\
\hline$\gamma_{b}=1.2, \kappa=6.612$ & & & & & \\
Consumption tax rate & - & 0 & 0 & 0.446 & 0.220 \\
Labour income tax rate & - & -0.056 & 0.227 & 0 & 0 \\
Hours worked, Income & 0.275 & 0.253 & 0.221 & 0.210 & 0.229 \\
Leisure & 0.725 & 0.747 & 0.779 & 0.790 & 0.771 \\
Consumption & 0.231 & 0.223 & 0.187 & 0.176 & 0.192 \\
Government Spending & 0.044 & 0.030 & 0.034 & 0.034 & 0.037 \\
Public debt & - & 0.304 & 0.298 & 0.252 & 0.196 \\
Public debt price & - & 1.160 & 0.973 & 1.058 & 0.973 \\
Consumption-income ratio & 0.839 & 0.881 & 0.845 & 0.839 & 0.839 \\
Public spending-income ratio & 0.161 & 0.119 & 0.154 & 0.161 & 0.161 \\
Public debt-income ratio & - & 1.200 & 1.348 & 1.200 & 0.856 \\
Welfare-eq. consumption loss & 0 & & 0.049 & & 0.038 \\
\hline & & & & & \\
\hline
\end{tabular}


Table 5: Tax Rates and Allocations, Frisch Elasticity

\begin{tabular}{l|c|c|c|c|c} 
& First Best & \multicolumn{2}{|c|}{ Labour Income Tax } & \multicolumn{2}{|c}{ Consumption Tax } \\
Variable & & $t=0$ & $t \geq 1$ & $t=0$ & $t \geq 1$ \\
\hline$\varphi=0.5, \kappa=16.028$ & & & & & \\
Consumption tax rate & - & 0 & 0 & 0.361 & 0.207 \\
Labour income tax rate & - & 0.110 & 0.208 & 0 & 0 \\
Hours worked, Income & 0.275 & 0.248 & 0.240 & 0.234 & 0.244 \\
Leisure & 0.725 & 0.752 & 0.760 & 0.765 & 0.756 \\
Consumption & 0.231 & 0.213 & 0.202 & 0.197 & 0.205 \\
Government Spending & 0.044 & 0.035 & 0.038 & 0.038 & 0.039 \\
Public debt & - & 0.159 & 0.167 & 0.127 & 0.111 \\
Public debt price & - & 1.023 & 0.973 & 1.054 & 0.973 \\
Consumption-income ratio & 0.839 & 0.858 & 0.843 & 0.839 & 0.839 \\
Public spending-income ratio & 0.161 & 0.142 & 0.157 & 0.161 & 0.161 \\
Public debt-income ratio & - & 0.640 & 0.697 & 0.640 & 0.453 \\
Welfare-eq. consumption loss & 0 & & 0.029 & & 0.023 \\
\hline$\varphi=5, \kappa=3.923$ & & & & & \\
Consumption tax rate & - & 0 & 0 & 0.251 & 0.211 \\
Labour income tax rate & - & -0.036 & 0.204 & 0 & 0 \\
Hours worked, Income & 0.275 & 0.237 & 0.195 & 0.198 & 0.203 \\
Leisure & 0.725 & 0.763 & 0.805 & 0.802 & 0.797 \\
Consumption & 0.231 & 0.208 & 0.166 & 0.166 & 0.171 \\
Government Spending & 0.044 & 0.029 & 0.029 & 0.032 & 0.033 \\
Public debt & - & 0.151 & 0.154 & 0.127 & 0.120 \\
Public debt price & - & 1.219 & 0.973 & 0.977 & 0.973 \\
Consumption-income ratio & 0.839 & 0.878 & 0.849 & 0.839 & 0.839 \\
Public spending-income ratio & 0.161 & 0.122 & 0.151 & 0.161 & 0.161 \\
Public debt-income ratio & - & 0.640 & 0.787 & 0.640 & 0.589 \\
Welfare-eq. consumption loss & 0 & & 0.075 & & 0.060 \\
\hline & & & & & \\
\hline
\end{tabular}


Table 6: Tax Rates and Allocations, Non-Separable Preferences

\begin{tabular}{l|c|c|c|c|c} 
& First Best & \multicolumn{2}{|c|}{ Labour Income Tax } & \multicolumn{2}{c}{ Consumption Tax } \\
Variable & & $t=0$ & $t \geq 1$ & $t=0$ & $t \geq 1$ \\
\hline$\sigma=2, \kappa=4.408$ & & & & & \\
Consumption tax rate & - & 0 & 0 & 0.264 & 0.210 \\
Labour income tax rate & - & -0.013 & 0.207 & 0 & 0 \\
Hours worked, Income & 0.275 & 0.244 & 0.212 & 0.213 & 0.219 \\
Leisure & 0.725 & 0.756 & 0.788 & 0.787 & 0.781 \\
Consumption & 0.231 & 0.212 & 0.180 & 0.179 & 0.184 \\
Government Spending & 0.060 & 0.032 & 0.033 & 0.034 & 0.035 \\
Public debt & - & 0.156 & 0.163 & 0.136 & 0.126 \\
Public debt price & - & 1.178 & 0.973 & 0.982 & 0.973 \\
Consumption-income ratio & 0.839 & 0.869 & 0.846 & 0.839 & 0.839 \\
Public spending-income ratio & 0.161 & 0.131 & 0.154 & 0.161 & 0.161 \\
Public debt-income ratio & - & 0.640 & 0.766 & 0.640 & 0.575 \\
Welfare-eq. consumption loss & 0 & & 0.055 & & 0.044 \\
\hline$\sigma=0.5, \kappa=8.815$ & & & & & \\
\hline Consumption tax rate & - & 0 & 0 & 0.350 & 0.207 \\
Labour income tax rate & - & 0.117 & 0.208 & 0 & 0 \\
Hours worked, Income & 0.275 & 0.246 & 0.238 & 0.232 & 0.242 \\
Leisure & 0.725 & 0.754 & 0.762 & 0.768 & 0.758 \\
Consumption & 0.231 & 0.212 & 0.201 & 0.195 & 0.203 \\
Government Spending & 0.060 & 0.034 & 0.037 & 0.037 & 0.039 \\
Public debt & - & 0.157 & 0.164 & 0.149 & 0.112 \\
Public debt price & - & 1.021 & 0.973 & 1.051 & 0.973 \\
Consumption-income ratio & 0.839 & 0.861 & 0.844 & 0.839 & 0.839 \\
Public spending-income ratio & 0.161 & 0.139 & 0.156 & 0.161 & 0.161 \\
Public debt-income ratio & - & 0.640 & 0.688 & 0.640 & 0.463 \\
Welfare-eq. consumption loss & 0 & & 0.032 & & 0.025 \\
\hline & & & & &
\end{tabular}

